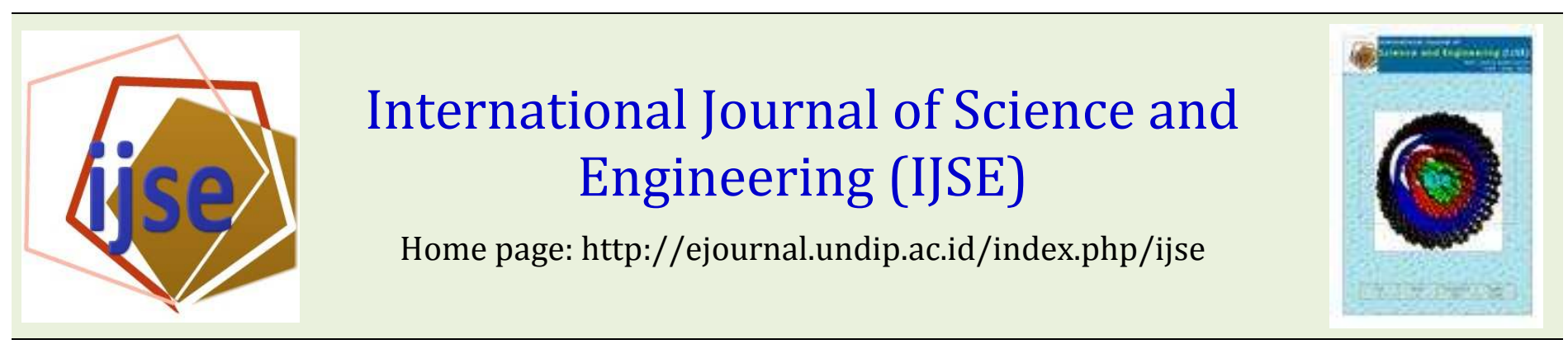

\title{
Dynamic Mechanical and Gel Content Properties of Irradiated ENR/PVC blends with $\mathrm{TiO}_{2}$ Nanofillers
}

\author{
Nur Azrini Ramlee*1, Chantara Thevy Ratnam², Nur Hashimah Alias ${ }^{1}$, Mohd Faizal Abd Rahman ${ }^{2}$ \\ 1 Faculty of Chemical Engineering, University Technology MARA Shah Alam, 40450 Shah Alam, Selangor, Malaysa. \\ 2 Malaysian Nuclear Agency (Nuclear Malaysia), Bangi, 43000 Kajang, Malaysia. \\ Coorresponding Author: azrini@salam.uitm.edu.my
}

\begin{abstract}
Numerous studies reported on irradiated epoxidized natural rubber/polyvinyl chloride (ENR/PVC) blends and the blends were found miscible at all compositional range thus it offers a broad of opportunity in modifying the blend characteristic. Addition of low loading titanium dioxide $\left(\mathrm{TiO}_{2}\right)$ nanofillers in the ENR/PVC blends has shown a remarkable increment in tensile strength. Thus, this study was initiated to address the effect of $\mathrm{TiO}_{2}$ nanofillers on ENR/PVC blends dynamic mechanical and gel content properties and its morphology upon exposure to electron beam irradiation. ENR/PVC blends with addition of 0,2 and $6 \mathrm{phr} \mathrm{TiO}_{2}$ nanofillers were first blended in a mixing chamber before being

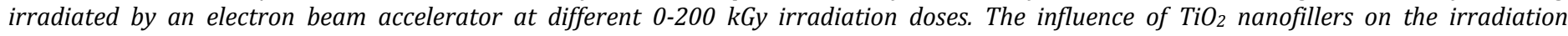
crosslinking of ENR/PVC blends was study based on the dynamic mechanical analysis which was carried out in determining the glass transition temperature and the storage modulus behavior of ENR/PVC blends incorporated with $\mathrm{TiO}_{2}$ nanofillers. Formations of irradiation crosslinking in the blend were investigated by gel content measurement. While, the TiO 2 nanofillers distribution were examined by Transmission Electron Microscope (TEM). Upon irradiation, the ENR/PVC/6 phr TiO 2 formed the highest value of gel fraction. For dynamic mechanical analysis, it was found that electron beam radiation increased the $\mathrm{Tg}$ of all the compositions. The relationship between the crosslinking and the stiffness of the nanocomposites also can be found in this study. The enhancement in the storage modulus and Tg at higher amount of TiO 2 in the blend could be correlated to the enhancement of the irradiation-induced crosslinking in the nanocomposites characteristic and also with the higher agglomerations of $\mathrm{TiO}_{2}$ evidence shown from the TEM micrograph examination. Lastly, the dimensions of $\mathrm{TiO}_{2}$ in the blends were found less than $100 \mathrm{~nm}$ in diameter which indicates incorporation of $\mathrm{TiO}_{2}$ nanofillers in ENR/PVC blends is potentially to provide the nanocomposites features.
\end{abstract}

Key words $-\mathrm{TiO}_{2}$ nanofillers, irradiated ENR/PVC, electron beam radiation, nanocomposites.

Submission: September 14, $2013 \quad$ Corrected : November 9, 2013

Accepted: November 12, 2013

Doi: $10.12777 /$ ijse.6.1.24-30

[How to cite this article: Ramlee, N.A., Ratnam, C.T., Alias, N.H ${ }^{1}$, Rahman, M.F.A.. 2014. Dynamic Mechanical and Gel Content Properties of Irradiated ENR/PVC blends with $\mathrm{TiO}_{2}$ Nanofillers. International Journal of Science and Engineering, 6(1),24-30. Doi: 10.12777/ijse.6.1.24-30]

\section{Introduction}

Several studies on irradiated ENR/PVC blends had proved that these blends are miscible at all compositional range and thus offers a great interest in preparing an engineering composite material use such in medical devices manufacturing and automotive industry. Polymer composite systems have a large scale for industry or research area due to the light weight, design flexibility and process robustness characteristics. Incorporation of fillers create an alternative approaches in developing a new polymer composites with better performances due to their outstanding mechanical properties. In attempt to improve the mechanical strength of the polymer blend, nanocomposite inorganic filler become commercially available.

Nanocomposite fillers where the particle size tends to be $<100 \mathrm{~nm}$ is seen to be emerging as a replacement for the conventional fillers. They are effective as reinforcing fillers at lower concentrations and are therefore cheaper to use. In addition, in early studies some nanocomposite fillers appear to impart antioxidant effects, photostability, and flame retardant to the composite [1]. Filler distribution affects the properties of the blend, as it is controlled by the molecular weight of the polymer and filler dispersion in each phase and chemical interaction between polymer and filler [2]. Some researcher verified that the use of fillers can significantly affect the UV-induced degradation of a polymer material [37]; for instance, in rigid PVC compounds, it is the titanium dioxide $\left(\mathrm{TiO}_{2}\right)$ added to the formulation that is responsible for its UV resistance and its outdoor lifetime.

$\mathrm{TiO}_{2}$ is an inorganic particles and it presents special features such as self cleaning, photovoltaic, anti bacterial and UV protector offers tremendous improvement in performance properties of the polymer matrix. In year 2005, Kamisli and Turan [8] has found that additional of $\mathrm{TiO}_{2}$ in PVC composition has reduced the effective depth penetration of ultraviolet light into the surface of an article formed from such a composition. On the other part, study on mechanical strength of irradiated ENR/PVC incorporation at lower 
loading of $2 \mathrm{phr} \mathrm{TiO}_{2}$ nanofillers has been carried out and the scientific outomes revealed that high tensile strength were performed at the highest irradiation exposure [9] on the polymer matrix.

Thus, this present study extends to look into the dynamic mechanical analysis, gel content and the distribution of $\mathrm{TiO}_{2}$ nanofillers at different exposure of radiation dose and varies of $\mathrm{TiO}_{2}$ nanofillers loading. The effects of 2 and 6 phr $\mathrm{TiO}_{2}$ nanofillers addition via melt blending technique on dynamic mechanical analysis and morphological properties of 50/50 ENR/PVC blends were investigated. The properties of the ENR/PVC incorporated with $\mathrm{TiO}_{2}$ nanofillers which were irradiated at different dose rate in range of 0-200 kGy were also discussed.

\section{Materials and Methods}

\section{A. Materials}

Epoxidised natural rubber, grade "Epoxyprene 50" with $50 \%$ epoxidation level was obtained from Malaysian Rubber Board (MRB), polyvinyl chloride (PVC) with a $<\mathrm{Mn}>$ of 66,000 , grade "MH66,6519" was purchased from Industrial Resin (M) Ltd. The Tin stabilizer which issued to stabilizer the PVC, was purchased from Polymer Resources Sdn. Bhd. They were used as received. The $\mathrm{TiO}_{2}$ investigated in this study was supplied by the Sigma Aldricha and its diameter less than $100 \mathrm{~nm}$.

\section{B. Blending Preparation}

Melt blending was carried out at $150{ }^{\circ} \mathrm{C}$ and $50 \mathrm{rpm}$ rotor speed with a Brabender Plastograph W50 E-3 Zones. The blending was prepared as shown in Table 1. ENR-50 was charged into the mixing chamber for 1 minute before it was added with PVC compound. After 5 minutes of blending, $\mathrm{TiO}_{2}$ was charged into the mixer. The mixing was continued for another 5 minutes. The blends obtained from the Brabender Plastograph were compression molded into $1 \mathrm{~mm}$ thick sheets under a pressure of 130 bars at $160{ }^{\circ} \mathrm{C}$ for 3 minutes. The sheets were immediately cooled between two plates of a cold press.

\section{Blending Radiation}

The molded sheets were irradiated using a $3 \mathrm{MeV}$ electron beam accelerator at a dose range of 0-200 kGy. The acceleration energy, beam current, and dose rate are $3 \mathrm{MeV}$, $5 \mathrm{~mA}$, and $50 \mathrm{kGy} /$ pass, respectively.

\section{Characterization of ENR/PVC/TiO ${ }_{2}$ nanocomposites}

Upon radiation, irradiated $\mathrm{ENR} / \mathrm{PVC} / \mathrm{TiO}_{2}$ samples were then characterized based on the gel content measurement, dynamic mechanical analysis (DMA), and transmission electron microscope (TEM) examination.

\section{Measurement of Gel Content}

Gel content measurement represents the crosslink density of polymer in which the higher the value of gel content the higher amount of crosslinking in the polymer. The gel content of the crosslinked samples was determined by the extraction of samples in tetrahydrofuran (THF) solvent at $50 \pm 2{ }^{\circ} \mathrm{C}$. The samples were extracted with solvent
THF for 24 hours and the extracted samples were dried till constant weight. The gel fraction is calculated as:

$\%$ Gel content $=(\mathrm{W} / \mathrm{Wo}) \times 100$

Where, $\mathrm{W}$ and Wo are the weights of the dried samples after extraction and the weight of the sample before extraction, respectively.

\section{Dynamic Mechanical Analysis}

In order to determine the glass transition temperature (Tg) and modulus behavior, dynamic mechanical analysis (DMA) was performed using Perkin-Elmer DMA-7e in the temperature/time scan mode with a parallel plate attachment. The measurements were carried out at a heating rate of $10^{\circ} \mathrm{C} / \mathrm{min}$ over a temperature range of -100 to $100{ }^{\circ} \mathrm{C}$ and a frequency of $1 \mathrm{~Hz}$.

\section{Transmission Electron Microscopy (TEM)}

Samples were characterized by transmission electron microscopy (TEM) using Jeol-JEM-2100 TEM. Macroscopic level analyses of each of component blends were examined at 15000x, 20000x and 40000x magnification.

Table 1. ENR/PVC/TiO 2 blend compositions

\begin{tabular}{|l|c|c|c|}
\hline ENR & 50 & 50 & 50 \\
\hline PVC & 50 & 50 & 50 \\
\hline $\mathrm{TiO}_{2}$ & 0 & 2 & 6 \\
\hline
\end{tabular}

\section{Results and Discussion}

\section{Gel Content Measurement}

The effect of irradiation dose rate on the gel content measurement of ENR/PVC blends with addition of $\mathrm{TiO}_{2}$ nanofillers are shown in Figure 1. It is clearly showed the gel content of the all compositions increased with the addition of $\mathrm{TiO}_{2}$ nanofillers loading and upon exposure of all blends to the higher irradiation dose rate. The gel content of blends with the presence of $\quad 6$ phr $\mathrm{TiO}_{2}$ nanofillers is much higher compared to the blends of $2 \mathrm{phr} \mathrm{TiO}_{2}$ nanofillers loading. Higher degree of crosslinking are expected to achieved for $6 \mathrm{phr} \mathrm{TiO}_{2}$ nanofillers loading since its present will further enhance the irradiation-induced crosslinking in the ENR/PVC matrix. As mentioned by Friedrich et al. [10], inorganic particles are well known to enhance the properties of polymer.

Apart from that, the highest gel content was obtained when all compositions were exposed to irradiation dose rate of $200 \mathrm{kGy}$. Thus, this shows an increase in gel content with the irradiation induced is an indication of formation of crosslinking in the blends. However the increment of the gel content of all compositions is less remarkable when the compositions exposed to high irradiation effect. This is due to the crosslinking and scission effects [11] that might occur in the ENR/PVC matrix when it was being exposed to the high dose rate. 


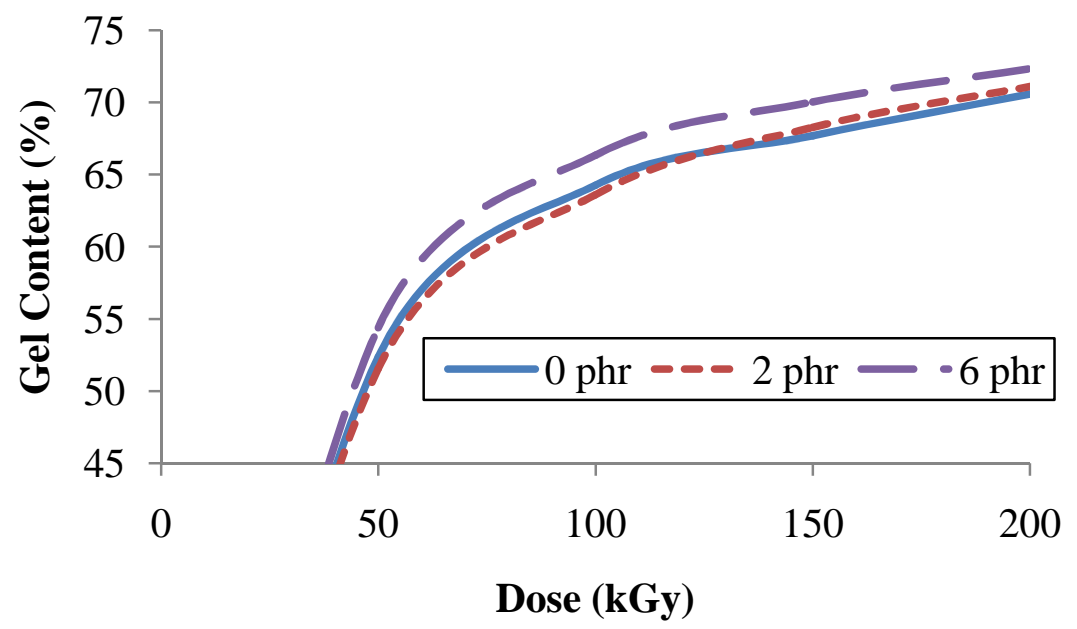

Figure 1. Gel content of irradiated ENR/PVC blends with addition of 0,2 and 6 phr $\mathrm{TiO}_{2}$ nanofillers.

\section{Dynamic Mechanical Analysis Tan Delta $(\delta)$}

Tan delta $(\delta)$ is a measure of the ratio of dissipated energy as heat to the maximum energy stored in the material during one cycle of oscillation. From Figure 2.-Figure 4., $\tan \delta$ values of irradiated ENR/PVC blends with addition of 0,2 and $6 \mathrm{phr} \mathrm{TiO}_{2}$ nanofillers were varied and it increased upon 200 kGy radiation effect and also with addition of higher loading of $\mathrm{TiO}_{2}$ nanofillers. At higher loading of $6 \mathrm{phr} \mathrm{TiO}_{2}$ nanofillers, the nanofillers presence reduce the composite elastic behavior, caused the elastic system dissipated more energy as heat and forms high tan $\delta$ peak.

For all $\mathrm{TiO}_{2}$ nanofillers loading compositions, it is showed that in the presence of irradiation, sharp $\tan \delta$ peak were obtained compared to non-irradiated samples. A sharp $\tan \delta$ peak is clear evidence of high intermolecular interactions with minimum intermolecular chemical heterogeneity in 50/50 ENR/PVC blends [12].

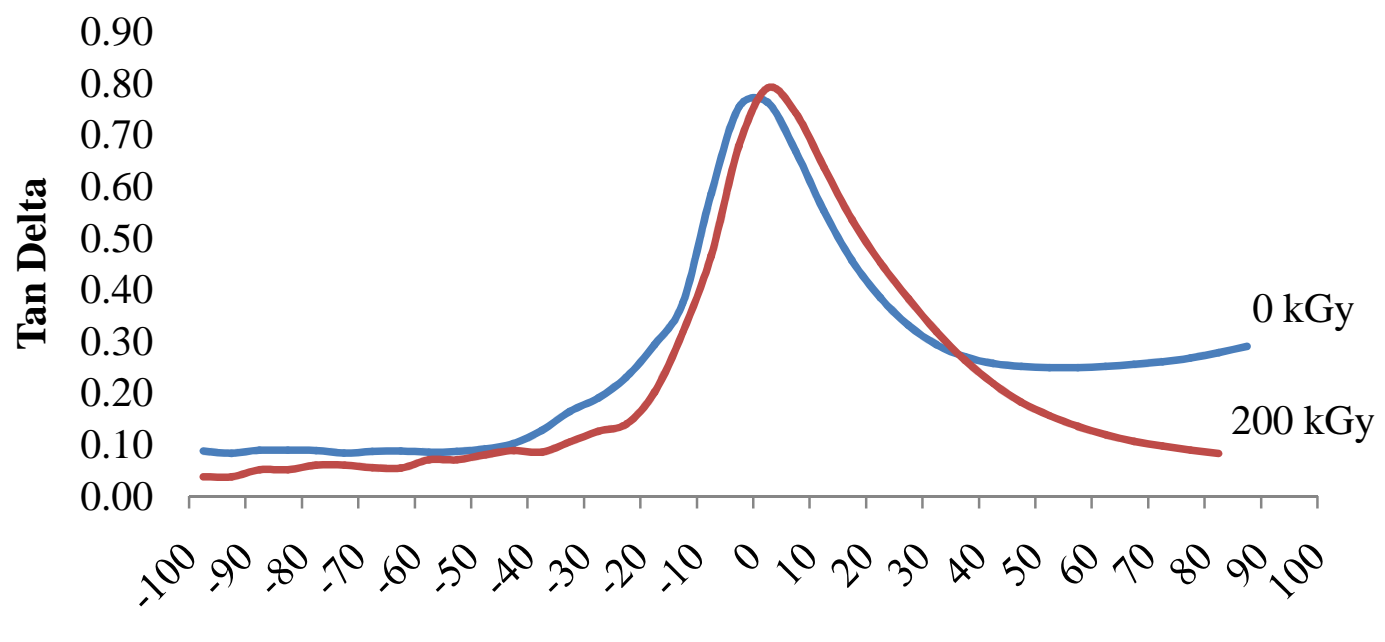

Temperature $\left({ }^{\circ} \mathbf{C}\right)$

Figure 2. Temperature dependence of $\tan \delta$ of $\mathrm{ENR} / \mathrm{PVC} / 0 \mathrm{phr} \mathrm{TiO}_{2}$ nanofillers at $0 \mathrm{kGy}$ and 200 kGy radiation dose. 


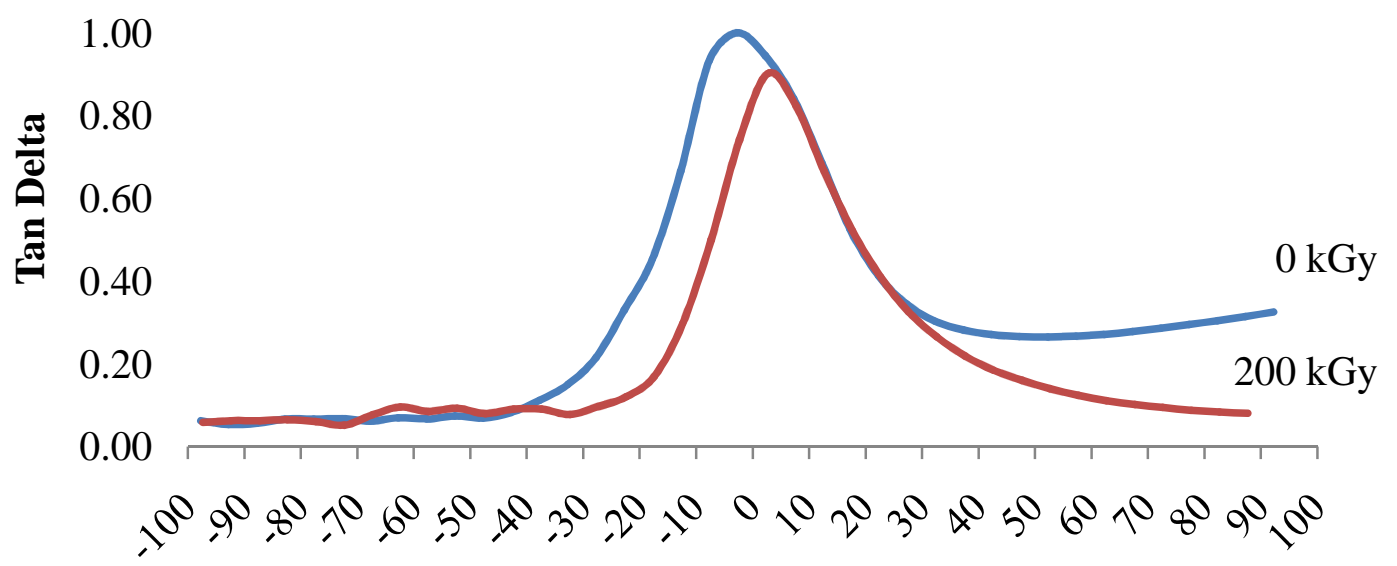

Temperature $\left({ }^{\circ} \mathbf{C}\right)$

Figure 3. Temperature dependence of $\tan \delta$ of $\mathrm{ENR} / \mathrm{PVC} / 2 \mathrm{phr} \mathrm{TiO}_{2}$ nanofillers at $0 \mathrm{kGy}$ and 200 kGy radiation dose.

Apart from that, the tan $\delta$ curves show the presence of a single peak and this correspondence to irradiated ENR/PVC blends of high miscibility characteristic. The temperature corresponding to the maximum in $\tan \delta$ is taken as glass transition ( $\mathrm{Tg}$ ) of the blend [13]. Tg of the blend for all compositions is shifted to higher temperature with irradiation. Without irradiation, the ENR/PVC/6 phr $\mathrm{TiO}_{2}$ nanofillers showed that the temperature at (tan $\delta)_{\max }$ is $-2.531{ }^{\circ} \mathrm{C}$ and it shifted to $2.159^{\circ} \mathrm{C}$ upon irradiation of $200 \mathrm{kGy}$. Similar trend was observed for ENR/PVC blends incorporated with $2 \mathrm{phr} \mathrm{TiO}_{2}$ nanofillers. While, only slight $(\tan \delta)_{\max }$ of $2.536{ }^{\circ} \mathrm{C}$ to $2.548{ }^{\circ} \mathrm{C}$ was obtained for nonirradiated sample. This observation was believed to be associated with the crosslinking induced by the irradiation. As mentioned by Ratnam [14] in the study of PVC/ENR blends, the physical and mechanical properties of the blend could be enhanced by EB radiation.
High $\tan \delta$ peak and low Tg values obtained for $6 \mathrm{phr}$ $\mathrm{TiO}_{2}$ nanofillers loading composition (as shown in Figure 4.) and this is believed to be associated with the effect of high amount of $\mathrm{TiO}_{2}$ introduced in ENR/PVC matrix. Such observation suggests $\mathrm{TiO}_{2}$ nanofillers provide an ease processing for ENR/PVC melt blending at lower temperature and high amount of this nanofillers in the ENR/PVC blends caused an occurrence of breaker to polymer chain that ruptures the crosslink structure. Meanwhile, $\mathrm{Tg}$ of the blend is decreased when too much addition of $\mathrm{TiO}_{2}$ into the blend due to the occurrence of breaker or mobility to the chain that rupture the crosslink structure. As mentioned by Zoppi et al. [15], the degree of crystallinity of the polymeric matrix slightly decreased with the incorporation of an amorphous inorganic phase, $\mathrm{TiO}_{2}$ into copolymer between polyamide- 6 and poly (ethylene oxide).

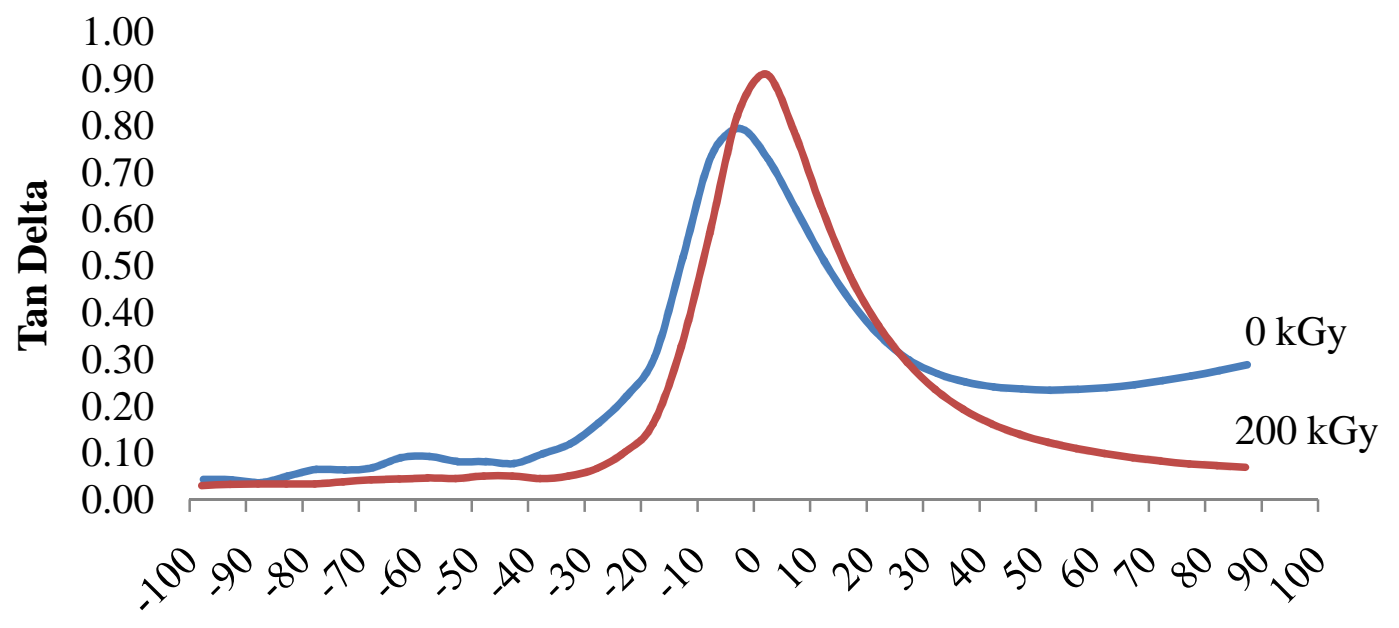

Temperature $\left({ }^{\circ} \mathbf{C}\right)$

Figure 4. Temperature dependence of $\tan \delta$ of ENR/PVC/6 phr $\mathrm{TiO}_{2}$ nanofillers at $0 \mathrm{kGy}$ and $200 \mathrm{kGy}$ radiation dose. 


\section{Storage Modulus}

The change in storage modulus of all compositions upon irradiation of $0 \mathrm{kGy}$ and $200 \mathrm{kGy}$ is presented in Figure 5. and Figure 6. Storage modulus represents the stiffness of the irradiated blends. Thus, it is obviously illustrated the highest storage modulus was obtained from ENR/PVC/6 phr $\mathrm{TiO}_{2}$ nanofillers samples irradiated at $0 \mathrm{kGy}$ and $200 \mathrm{kGy}$. The increase of storage modulus is significant at low temperature. Exposure to $200 \mathrm{kGy}$ irradiation has induced the crosslinking in the ENR/PVC blends thus improved the storage modulus performance of ENR/PVC/0 phr $\mathrm{TiO}_{2}$ nanofillers. In addition, incorporation of higher nanofillers loading has further increased the stiffness of the composites by transferring the stiffness characteristic of $\mathrm{TiO}_{2}$ nanofillers to the ENR/PVC matrix as shown in Figure 6. Similar trends were reported by Esthappan [16] when $\mathrm{TiO}_{2}$ nanofillers has been introduced in single polypropylene matrix in which provided efficient stress transfer between the polymer matrix and $\mathrm{TiO}_{2}$. Due to poor degree of crosslinked, low storage modulus of non-irradiated samples with $0 \mathrm{phr} \mathrm{TiO}_{2}$ nanofillers loading is expected since the composition has shown poor gel content properties results.

Nevertheless, at $6 \mathrm{phr} \mathrm{TiO}_{2}$ nanofillers loading, it is clearly seen that there is no significant differences in the storage modulus upon irradiation of $0 \mathrm{kGy}$ and $200 \mathrm{kGy}$. Drop in the storage modulus values of ENR/PVC/2phr $\mathrm{TiO}_{2}$ nanofillers were observed and this may be due to low loading of $\mathrm{TiO}_{2}$ nanofillers and also the exposure of samples to high dose rate caused high scission or crosslinking effect on the ENR/PVC polymer crosslinking [17] which support the above findings.

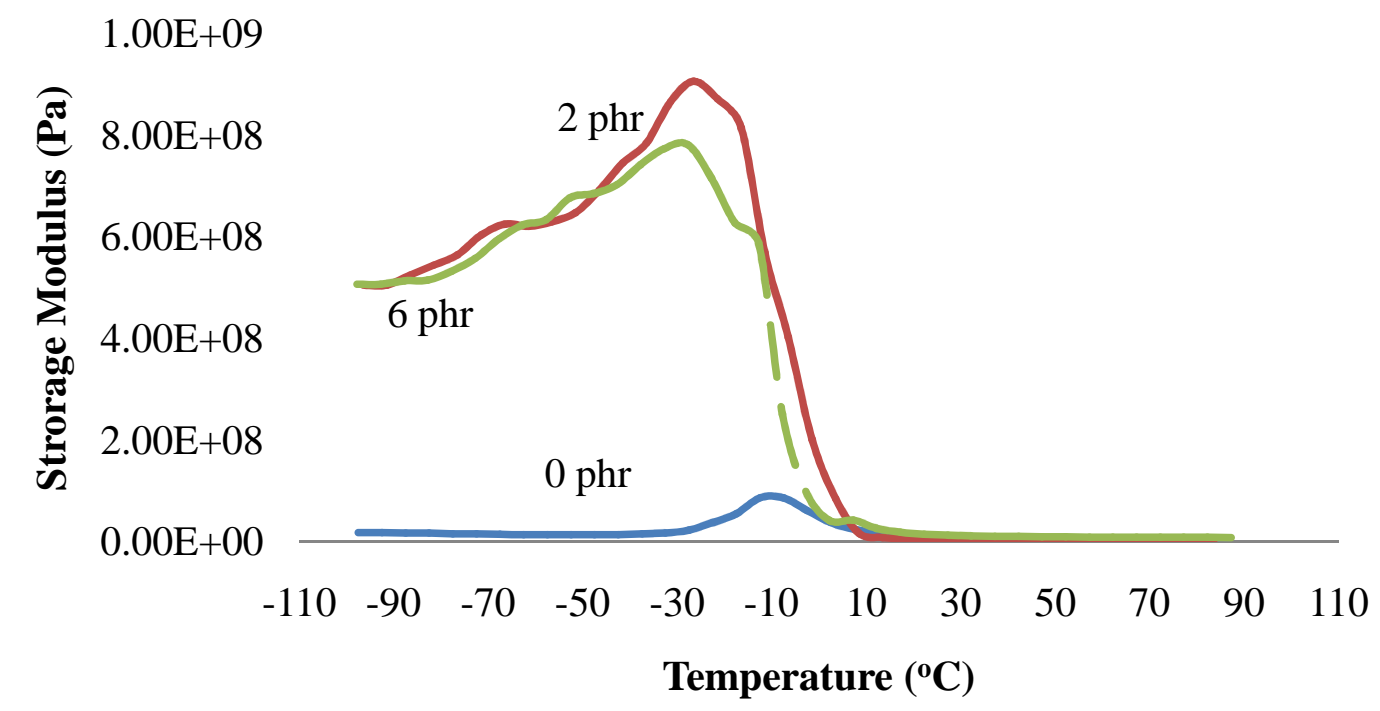

Figure 5. The temperature dependence of storage modulus of ENR/PVC with $\mathrm{TiO}_{2}$ nanofillers loading at $0 \mathrm{kGy}$ radiation dose.

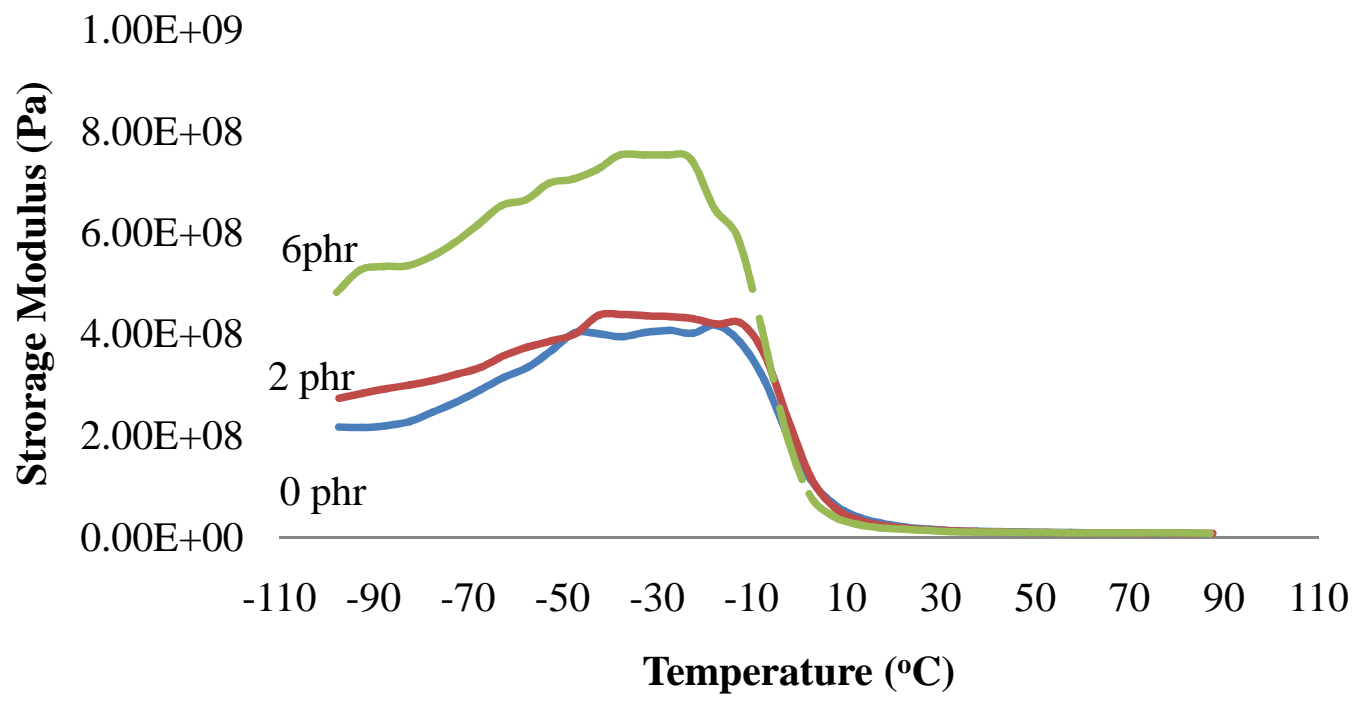

Figure 6. The temperature dependence of storage modulus of ENR/PVC with $\mathrm{TiO}_{2}$ nanofillers addition at $200 \mathrm{kGy}$ radiation dose. 


\section{Dispersion of $\mathrm{TiO}_{2}$ Nanoparticles}

Figure 7. illustrates the TEM micrographs for ENR/PVC/2 phr $\mathrm{TiO}_{2}$ and ENR/PVC/6 phr $\mathrm{TiO}_{2}$ which the samples have been exposed at different dose rate including 0 kGy, $100 \mathrm{kGy}$ and $200 \mathrm{kGy}$ radiation doses respectively. The lighter region represents ENR/PVC blends matrix while dark region represents the distribution of $\mathrm{TiO}_{2}$ nanofillers. Distribution and the presence of $\mathrm{TiO}_{2}$ nanofillers in the ENR/PVC blends matrix were found increased upon to the higher loading of the $\mathrm{TiO}_{2}$ nanofillers and these observation are expected to be attained since at $6 \mathrm{phr}$ of loading caused a lower $\mathrm{Tg}$ results.

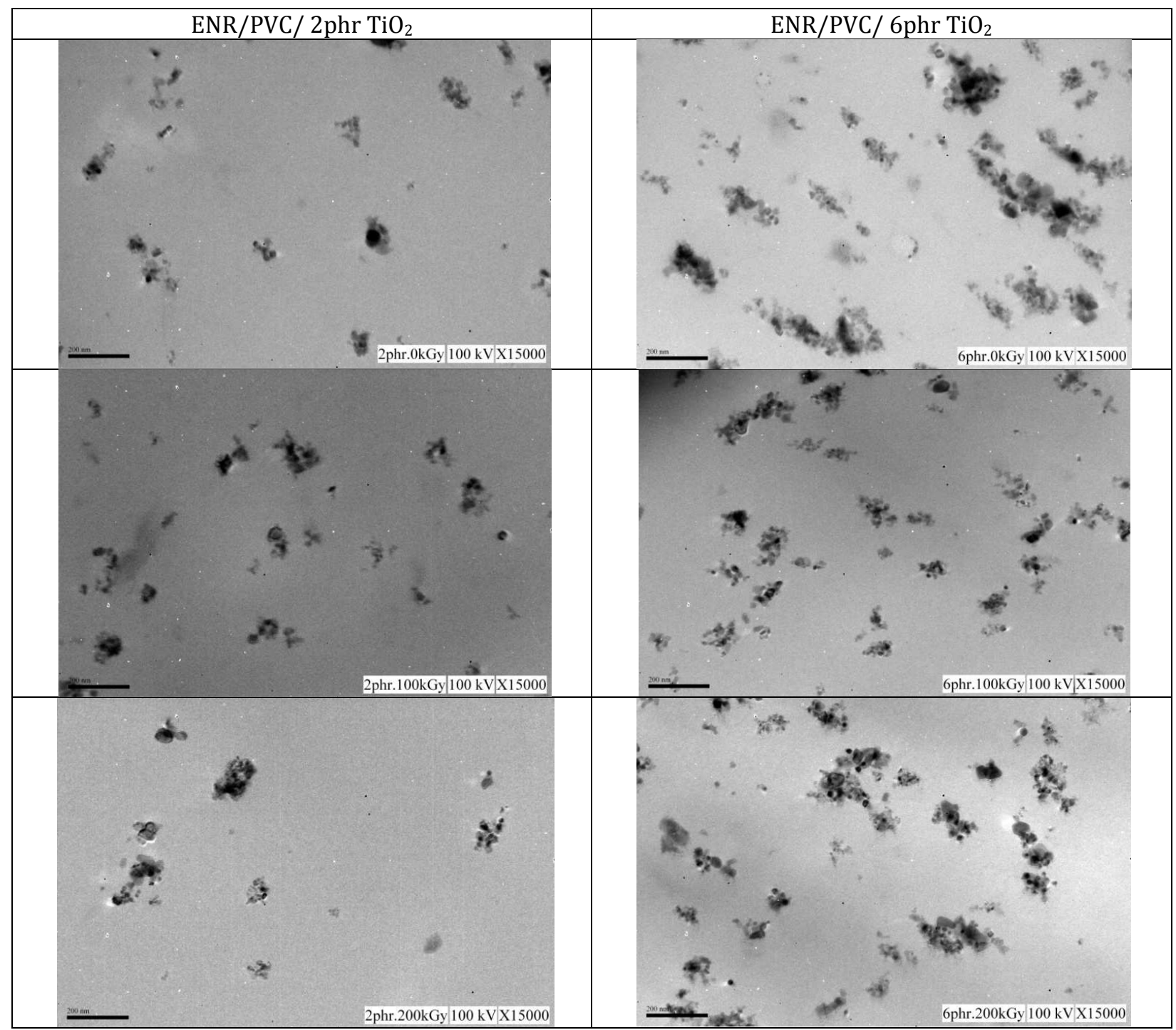

Figure 7. TEM micrograph with addition of $2 \mathrm{phr}$ and 6 phr of $\mathrm{TiO}_{2}$ into ENR/PVC-50 blend (15000X) at $100 \mathrm{kGy}$ and $200 \mathrm{kGy}$ of radiation dose.

\section{Conclusions}

Upon irradiation, the ENR/PVC/6 phr $\mathrm{TiO}_{2}$ formed the highest value of gel fraction. For dynamic mechanical analysis, it was found that electron beam radiation increased the Tg of all the compositions. The relationship between the crosslinking and the stiffness of the nanocomposites also can be found in this study. The enhancement in the storage modulus and $\mathrm{Tg}$ at higher amount of $\mathrm{TiO}_{2}$ in the blend could be correlated to the enhancement of the irradiation-induced crosslinking in the nanocomposites characteristic and also with the higher agglomerations of $\mathrm{TiO}_{2}$ evidence shown from the TEM micrograph examination. Lastly, the dimensions of $\mathrm{TiO}_{2}$ in the blends were found less than $100 \mathrm{~nm}$ in diameter which indicates incorporation of $\mathrm{TiO}_{2}$ nanofillers in ENR/PVC blends is potentially to provide the nanocomposites features.

\section{Acknowledgements}

The authors acknowledge the Universiti Teknologi Mara (UiTM) for granting the Excellence Fund (600-RMI/DANA 5/3/RIF (132/2012) to carry out this project. Special thank to Malaysia Nuclear Agency for the expertise, equipment and technical assistance in carrying out the experiments.

\section{References}

[1] Andrady, A. L., Hamid, H. S. and Torikai, A. (2006). Chapter 7. Effects of stratospheric ozone depletion and climate change on materials damage. In The Environmental Effects Assessment Panel Report, 185200. 
[2] Khalid, M., Ismail, A. F., Ratnam, C. T., Faridah, Y., Rashmi, W. and Al Khatib, M. F. (2010). Effect of radiation dose on the properties of natural rubber nanocomposite. Radiation Physics and Chemistry. 79: 1279:1785.

[3] Mosurkal, R., Samuelson, L. A, Smith, K. D, Parmar, V. S. and Yan, F. (2008). Nanocomposites of $\mathrm{TiO}_{2}$ and siloxane copolymer as environmentally safe flame retardant materials. Journal of Macromolecular Science Part A Pure and Applied Chemistry, 45:924946.

[4] Nkayama, N. and Hayashi, T. (2007). Preparation and characterization of poly (L-lactic acid) $/ \mathrm{TiO}_{2}$ nanoparticle nanocomposite films with high transparency and efficient photodegradability. Polymer Degradation and Stability. 92:1255-1264.

[5] Kubacka, A., Serrano, C., Ferrer, M., Lunsdorf, H., Bielecki, P. and Cerrada, M. L. (2007). High Performance dual-action polymer-TiO nanocomposite films via melting processing. Nano Letters. 7:25292534.

[6] Pandey, J. K., Reddy, K. R., Kumar, A. P. and Singh, R. P. (2005). An overview on that degradability of polymer nanocomposites. Polymer Degradation and Stability. 898:234-250.

[7] Zeynalov, E. B., Allen, N. S., Calvet, N. L. and Stratton, J. (2007). Impact of stabilizers on the thermal catalytic activity of micro- and nanoparticle titanium dioxide in oxiding condensed mediums. Dyes and Pigments. 75:315-327.

[8] Kamisli, F. and Turan, C. (2005). A study on usability of magnesium oxide with titanium dioxide in PVC door and window profiles. Materials Processing Technology. 40-47.

[9] Ramlee, N. A., Ratnam, C. T., Abdul Rahman, S. and Abdul Samat, N. A. (2013). Incorporation of TiO2 nanoparticles in PVC/ENR blends. In Proceedings of the 2013 IEEE Business Engineering and Industrial
Applications Colloquium (BEAIC), 533-536. Langkawi, Malaysia: 2013 IEEE Business Engineering and Industrial Applications Colloquium.

[10] Friedrich, K., Zhang, Z. and Schlarb, A. K. (2005). Effects of various fillers on the sliding wear of polymer composites. Composites Science and Technology. 2329-2343.

[11] Zurina, M., Ismail, H. and Ratnam, C. T. (2006). Characterization of irradiation-induced crosslink of eposidisednatural rubber/ethylene vinyl acetate (ENR-50/EVA) blend. Polymer Degradation and Stability. 2723-2730.

[12] Ratnam, C. T. (2002). Enhancement of PVC/ENR blend properties by electron beam irradiation: effect of stabilizer content and mixing time. Polymer Testing. 21:93-100.

[13] Ratnam, C.T. (2001). Irradiation Crosslinking of PVC/ENR Blend: A Comparative Study with the Respective Homopolymers. Macromolecular Materials and Engineering. 429-433

[14] Ratnam, C.T., Raju, G. and Wan Yunus, W.M.Z. (2007). Oil palm empty fruit bunch (OPEFB) fiber reinforced PVC/ENR blend-electron beam irradiation. Nuclear Instruments and Methods in Physics Research. 510514.

[15] Zoppi, R.A., Neves, S. and Nunes, S.P. (2000). Hybrid films of poly(ethylene oxide-b-amide-6) containing sol-gel silicon or titanium oxide as inorganic fillers: effect of morphology and mechanical properties on gas permeability. Polymer. 41:5461-5470.

[16] Esthappan, K. (15 August 2013). Citing Internet sources URL shodhganga.inflibnet.ac.in/bitstream/10603/7995/13/13_chapter\% 206.pdf.

[17] Ratnam, C. T., Nasir, M., Baharin, A. and Zaman, K. (2001). The effect of electron beam irradiation on the tensile and dynamic mechanical properties of epoxidized natural rubber. European Polymer Journl. $37: 1667-1676$ 